\title{
A educação como kairós em Os Trabalhos e os Dias
}

\author{
Maria Cecilia Colombani ${ }^{1}$
}

\section{Resumo}

Este artigo propõe-se a analisar o conceito de kairós vinculado à ideia de educação. Pretende-se focar ambas as noções no contexto de Os Trabalhos e os Dias, para ver em que medida os conceitos adquirem um papel central na obra.

Escolhemos o tema porque hoje, mais do que nunca, a educação representa um verdadeiro kairós enquanto oportunidade, momento propício, ocasião favorável e oportunidade da transformação possível.

Escolhemos algumas passagens de Os Trabalhos e os Dias em que Hesíodo interpela seu irmão. Cremos que nessas situações se pode ler uma espécie de microcena didática pela qual se definem papéis específicos. Hesíodo opera como um mestre e seu irmão ocupa o lugar de um discípulo a quem é necessário reconverter em relação a certas condutas que se mostram contrárias a um modelo ético. Neste contexto, a educação representa a oportunidade da transformação possível.

\section{Palavras-chave}

Hesíodo, Os Trabalhos e os Dias, kairós, oportunidade, transformação

1 Professora Doutora, Universidade de Morón, Morón, Argentina. Email: ceciliacolombani@hotmail.com

Heródoto, Unifesp, Guarulhos, v. 5, n. 2 - 2020.2, p. 31-47.

DOI: $10.34024 /$ herodoto.2020.v5.12832 


\section{Resumen}

Este artículo analizará el concepto de kairós vinculado a la idea de educación. La propuesta es llevar ambas nociones al escenario de Trabajos Días para ver en qué medida los conceptos adquieren allí un lugar protagónico.

Elegimos el tema porque nos parece de absoluta actualidad, ya que hoy más que nunca la educación representa un verdadero kairós en tanto oportunidad, momento propicio, ocasión favorable, la oportunidad de alguna transformación posible.

Hemos escogido algunos pasajes de Trabajos y Días en los que Hesíodo interpela a su hermano. Creemos que allí se puede leer una especie de micro escena didáctica que define roles específicos. Hesíodo opera como un maestro y su hermano ocupa el lugar de un discípulo a quien es necesario reconvertir en relación con ciertas conductas que se visualizan como un contra modelo ético. En este marco, la educación representa la oportunidad de la transformación.

\section{Palabras clave}

Hesíodo, Trabajos y Días, kairós, educación, oportunidad, transformación

Heródoto, Unifesp, Guarulhos, v. 5, n. 2 - 2020.2, p. 31-47.

DOI: $10.34024 /$ herodoto.2020.v5.12832 


\section{Introdução}

Este artigo propõe-se a analisar o conceito de kairós vinculado à ideia de educação. A proposta é relacionar ambas as noções a Os Trabalhos e os Dias para verificar até que ponto os conceitos adquirem um lugar de destaque na obra.

Escolhemos o tema porque nos parece ser inteiramente atual, o que torna Hesíodo um clássico. Hoje, mais do que nunca, a educação representa um verdadeiro kairós enquanto oportunidade, momento propício, ocasião favorável.

A educação constitui sempre a oportunidade para alguma possível transformação. Diante do cenário de degradação moral que caracteriza a Idade do Ferro e do ensinamento exemplar que o mito das idades traz em sua história arquetípica, a educação se apresenta como o pilar da transformação.

Escolhemos algumas passagens de Os Trabalhos e os Dias nas quais Hesíodo interpela seu irmão. Acreditamos que ali podemos ler uma espécie de microcena didática onde são definidos papéis específicos.

Hesíodo opera como um professor e seu irmão ocupa o lugar de um discípulo que precisa ser reconvertido em relação a certos comportamentos que são vistos como um contramodelo ético.

Nesta estrutura, em que Perses se aproxima do perfil que Hesíodo rejeita, a educação representa a oportunidade para uma possível transformação.

\section{O Magistério}

The authority of the Works and Days resides principally in Hesiod's knowledge, rather than, as in Theogony, in that of the Muses; at the head of the poem he summons the Muses, not thowever to give him his song, but rather to sing of Zeus, while himself "will tell tru things to Perses". (Hunter, 2014: 47)

A Teogonia representa o poema emblemático para considerar Hesíodo como um mestre da verdade. Considerado por M. Detienne (1986) como a última testemunha de uma palavra destinada ao louvor do personagem real, o poeta inspirado pelas deliciosas filhas de Zeus ganha, de alguma forma, a visão do primordial, do que está na origem, no início, como condição de possibilidade

Heródoto, Unifesp, Guarulhos, v. 5, n. 2 - 2020.2, p. 31-47.

DOI: $10.34024 /$ herodoto.2020.v5.12832 
de tudo o que é. É a ele que as Musas disseram a verdade; elas, que são capazes de dizer coisas falsas sob o disfarce da verdade, escolhem o poeta para lhe dizer a verdade.

Nesta perspectiva, o poeta é um professor de aleteia que ensina a verdade porque ele ganha acesso a ela pelo seu dom de vidência (Colombani, 2016). O poeta chega à ciência de Mnemosine para saber o que foi, o que é e o que será. Este é o glorioso magistério herdado das Musas que se articula em um duplo canto, a teogonia e a cosmogonia que a palavra mágico-religiosa materializa na maravilhosa voz do poeta-mestre (Colombani, 2016).

Os Trabalhos e os Dias apresenta outro espetáculo não menos poderoso em termos de magistério poético. O texto tem outro espírito. Longe da teogonia como a história da genealogia divina ou da cosmogonia como a história do drama divino, ela nos conta as vicissitudes do trabalhador, bem como a consolidação progressiva da moralidade camponesa a partir de três eixos fundacionais que são o tema do ensino: justiça, virtude e trabalho, pilares sobre os quais se baseia o ensino moral.

É deste ponto que queremos nos aproximar a fim de demonstrar outra face do magistério, outro lado de um tipo de educação que se torna o kairós de uma nova subjetividade.

É novamente o poeta hesiódico que assume o desafio de consolidar um tipo de moral baseada em uma série de postulados básicos em matéria ética; ensinar a justiça como aquilo que curará a cidade, ensinar a virtude como aquele valor que tornará melhores os homens mortais e ensinar as bondades do trabalho como aquilo em que os elementos precedentes se materializam.

Hesíodo ocupa o lugar do professor. Sua autoridade o qualifica para este papel. O início da tarefa educacional implica em aceitar a capacidade de falar algumas verdades. Tal como na Teogonia, o poeta se estabelece como um professor/mestre de aleteia.

O campo lexical do verbo $\mu$ véoua desencadeia o desejo de Hesíodo de dizer, contar, narrar. O professor parte de um desejo que constitui o impulso para ensinar as verdades, غ̇ंท่to $\mu a$, que possui.

Assim como em Teogonia, o poeta narra a origem do real ao anunciar os quatro elementos primordiais, agora chegou a oportunidade de anunciar os

Heródoto, Unifesp, Guarulhos, v. 5, n. 2 - 2020.2, p. 31-47.

DOI: $10.34024 /$ herodoto.2020.v5.12832 
elementos constituintes de um território moral que permite a convivência dos

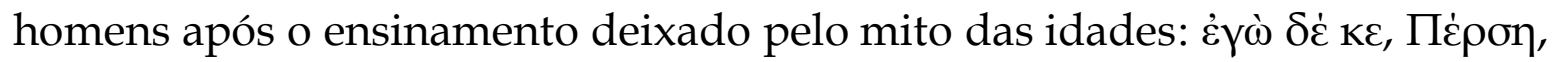

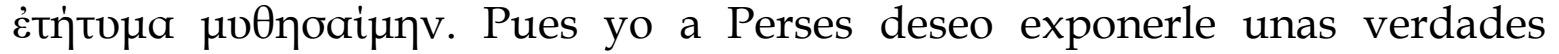
(Trabajos y Días, 10)

Descobrimos no poeta um desejo comunicacional de quem possui um duplo estatuto, a possibilidade de ensinar como professor e a posse de certas verdades para comunicar. Lembremos sempre que este legado é crucial quando se trata de interpretar seu papel, a partir da veiculação da verdade transmitida pelas Musas. Esta é a chave para a autoridade que as deusas conferem ao poeta. $\mathrm{O}$ mestre possui uma certa verdade e pode transmiti-la sob a forma de sugestões, conselhos e exortações.

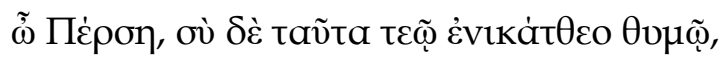

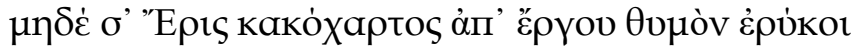

¡Oh, Perses! Tú guarda estas cosas en tu ánimo:

que la Discordia que se regocija con el mal ajeno no separe tu ánimo

del trabajo (Trabajos y Días, 27-28)

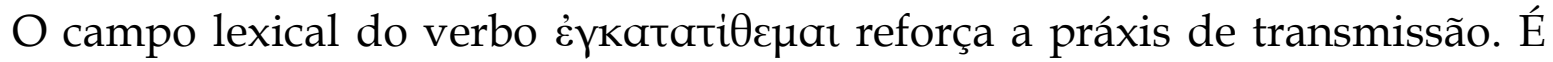
necessário ouvir os conselhos ou a verdade e manter no espírito. É uma prática antiga de ouvir quem sabe e capitalizar o aprendizado, mantendo-o seguro, guardando-o na memória para que possa retornar quando necessário. O que é aprendido funciona como uma reserva de sabedoria; daí que a educação se torne o kairós da consolidação de uma sabedoria de vida.

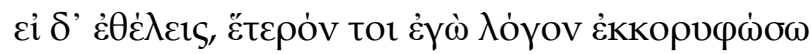

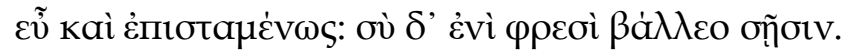

Y, si quieres, yo culminaré para ti con otro discurso

recta y sabiamente; y tú imprímelo en tu corazón (Trabajos y Días, 106-107)

Os versos reiteram o espírito do que constitui o coração da práxis educacional. Se os versos anteriores aludiam ao desejo do professor, agora o discípulo é convidado a aceitar o ensinamento. O campo lexical do verbo $\dot{\varepsilon} \theta \dot{\varepsilon} \lambda \omega$, desejar, querer, estar disposto, apetecer, supõe agora o impulso de quem deve aprender, escutar e valorizar um certo conhecimento. A chave é essa

Heródoto, Unifesp, Guarulhos, v. 5, n. 2 - 2020.2, p. 31-47.

DOI: $10.34024 /$ herodoto.2020.v5.12832 
disposição de espírito que permite que um certo aprendizado seja introjetado. Sem este desejo mútuo não pode haver educação.

O professor é capaz de culminar com outro discurso, ou seja, com outro ensinamento que será sem dúvida outro ponto de aprendizagem. A recomendação didática é sempre a mesma, já que a sugestão é gravá-la no coração. O campo lexical do verbo $\beta$ á $\lambda \lambda \omega$, por, colocar, está inscrito na exortação de valorizar aquilo que se sabe.

Agora, o que o professor ensina a um irmão que parece precisar de certas recomendações éticas baseadas em sua conduta? Antes de tudo, o valor da justiça como suporte para uma vida mais digna.

\section{A Justiça}

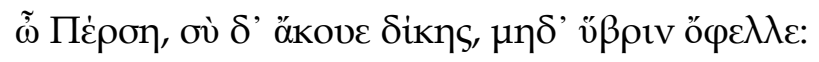

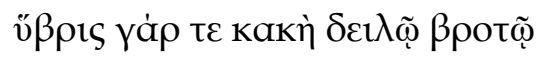

¡Oh Perses!, tú escucha a la justicia y no agrandes tu desmesura;

pues la desmesura es mala para el mísero mortal (Trabajos y Días, 213-214)

Dois imperativos abrem o campo persuasivo. O verbo ảkoú $\omega$ refere-se à ação de ouvir, escutar, saber pela escuta. Sem dúvida, a escuta é uma parte essencial do sistema educacional. Hesíodo insiste neste ponto porque somente aquele que é capaz de ouvir pode imprimir ou manter algo em seu espírito. $O$ segundo aviso é para não engrandecer os excessos, v̋ $\beta \rho \imath$. O verbo ò $\varphi \dot{\lambda} \lambda \lambda \omega$, aumentar, dilatar, multiplicar, adverte para o perigo da hybris quando ela aumenta. A história das idades já advertiu sobre sua devastação em questões de moral e é ela que tem cerzido a degradação antropológica, porque cada raça tem visto o aumento da própria imoderação como uma característica dominante.

O mito das raças nos traz de volta à progressiva decadência do homem a partir de um passado mais luminoso e, portanto, de um símbolo positivo, como parece transparecer do quadro que Hesíodo nos dá dos homens da raça de ouro. Ao mesmo tempo, a continuidade do mito das raças nos mostra como a decadência progressiva traz consigo a difícil viabilidade de um kósmos humano, subtendido pela ideia de justiça e concórdia.

Heródoto, Unifesp, Guarulhos, v. 5, n. 2 - 2020.2, p. 31-47.

DOI: $10.34024 /$ herodoto.2020.v5.12832 
Quando Hesíodo termina o relato do longo caminho de decadência e da injustiça, ele abre um panorama desolado do campo dos vínculos transitados pelo conflito (Neschke, 1996: 478)2.

É neste ponto que a primazia da hybris ofusca o reinado da justiça que deve prevalecer entre os homens a fim de alcançar o desejado kósmos que abriga todos os mortais em estado de harmonia. Daí a recomendação hesiódica de atender à justiça como uma forma didática de se tornar um homem melhor.

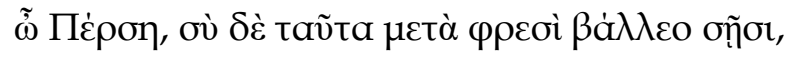

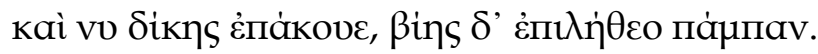

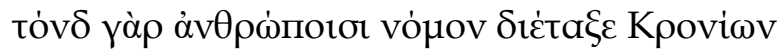

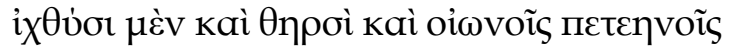

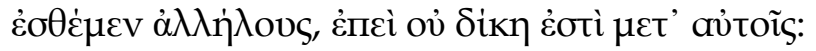

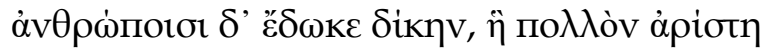

yirvetal

¡Oh Perses!, tú estas cosas guarda en tu corazón;

ahora escucha a la justicia, y olvida del todo la violencia.

Pues esta ley para los hombres dispuso el Cronión:

que los peces, las fieras y las aves aladas

se devoren unos a otros, puesto que la justicia no está entre ellos;

pero a los hombres dio la justicia, que enteramente óptima

es (Trabajos y Días, 274-280)

Mais uma vez, a perspectiva educacional, como ocasião propícia para a consolidação de uma humanidade melhor, está centrada no verbo ḋKoúw. É, de fato, a oportunidade de ouvir a justiça e esquecer a violência que a própria hybris carrega em seu valor negativo.

2 Concordamos com Neschke quando ele analisa o mito das raças a partir da perspectiva da exortação, da poesia didática, mas, também, da consolidação de uma moral.

Heródoto, Unifesp, Guarulhos, v. 5, n. 2 - 2020.2, p. 31-47.

DOI: $10.34024 /$ herodoto.2020.v5.12832 


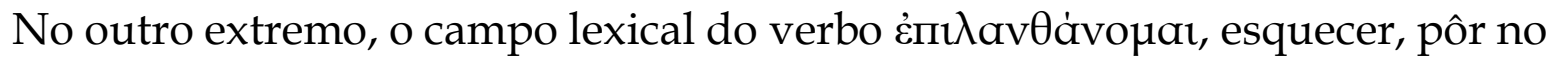
esquecimento, lança a oportunidade para a excelência. Esquecer a violência é a única maneira de a justiça se tornar soberana e este é o primeiro fundamento para um kósmos melhor.

Neste caso, será possível uma ação nesse sentido? É possível uma mudança de atitude que traria um novo modo de vida e, portanto, uma humanidade melhor no âmbito da educação como kairós?

A leitura feita pelos críticos, tendo à frente Olof Gigon (1985: 13-43), na qual nos baseamos e que seguimos como marco interpretativo, colocou Hesíodo naquela zona escura de fronteiras imprecisas entre poesia e filosofia, típica da Grécia arcaica; também trabalhou os núcleos filosóficos presentes na Teogonia como um relato emblemático da totalidade. O problema do ser, do todo, da origem, da verdade e da transmissão da verdade foram os fios que Gigon encontrou para tecer a tapeçaria do Hesíodo-filósofo. Nosso interesse é ampliar a linha de análise e ver como em Os Trabalhos e os Dias também encontramos fios que bordam esta mesma tapeçaria, fazendo de Hesíodo uma testemunha chave da transição entre a poesia, uma espécie de filosofia popular, de acordo com Louis Gernet, e a filosofia (1981: 16) ${ }^{3}$.

Acreditamos que esses versos apontam nesse sentido, distinguindo a natureza do homem e dos animais como universos distintos. É precisamente esse universo humano que pode se aproximar da ideia de justiça que dá a oportunidade para um mundo melhor.

A falta de justiça determina um mundo violento onde cada um devora o outro, mas os homens recebem a justiça como um verdadeiro dom. O campo lexical do verbo $\delta i \delta \omega \mu$, dar, outorgar, conceder, reforça a ideia do dom que Cronos deu aos homens. Esse dom é um kairós; a justiça é a oportunidade e ensiná-la é a ocasião favorável para atingir um mundo mais habitável. Essa

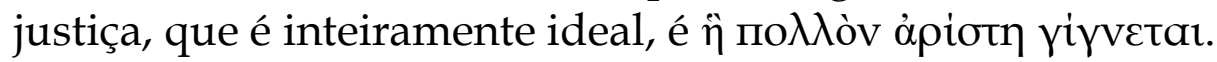

3 O autor alude à poesia como uma espécie de "filosofia popular" precisamente porque este logos arcaico dá conta a primeira organização do kósmos, como um grego perceberia, intuindo que por trás do caos aparente, se mantém uma certa legalidade que é fruto da ação dos deuses. Este tipo de "filosofia popular" anda de mãos dadas com uma visão otimista do mundo, que é o que prevalece na cidade. Os deuses nos reservam uma ordem-legalidade que pode ser intuída, mas não inteiramente visível.

Heródoto, Unifesp, Guarulhos, v. 5, n. 2 - 2020.2, p. 31-47.

DOI: $10.34024 /$ herodoto.2020.v5.12832 


\section{A Virtude}

A virtude é o outro pilar sobre o qual repousa a possibilidade de um mundo melhor. Ensinar a virtude é o segundo desafio do poeta-professor. A justiça e a virtude tornam-se o núcleo de uma preocupação pedagógica.

Os papéis são explícitos, e o adjetivo com o qual Hesíodo se refere a seu irmão aponta nessa direção. $\mathrm{O}$ adjetivo vínıs, jovem, infantil, ingênuo, menino, informa a própria condição de Perses; refere-se àquele que ainda não tem a capacidade de discernir. Ele é quem está no melhor estado para receber um ensinamento. Mais uma vez Hesíodo se apresenta como a pessoa que tem autoridade para dizer aquilo que se tornará um ensinamento, já que é qualificado por seu conhecimento sobre as coisas nobres.

O campo lexical do verbo غ̇ pedagógica. Seu resultado é a exposição do caminho da virtude no contexto do que poderíamos chamar de uma metáfora da viagem.

A virtude parece estar associada a um longo caminho que obedece a um telos final. É, portanto, um caminho teleológico que conhece outras instâncias antes de sua aquisição.

O caminho é íngreme e o mal é mais fácil de ser alcançado do que a excelência. A ilusão da maldade é que ela não só é facilmente encontrada, mas também é abundante.

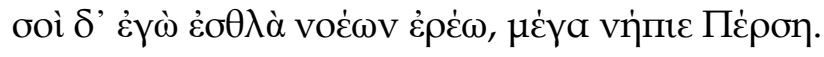

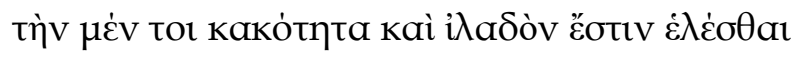

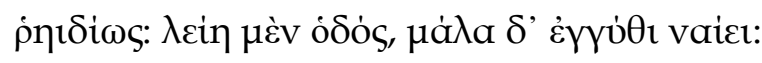

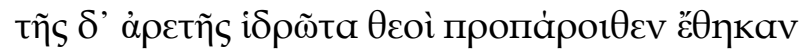

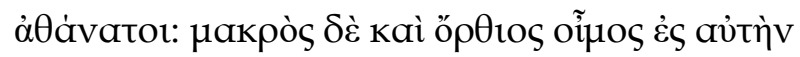

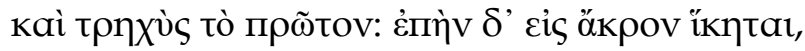

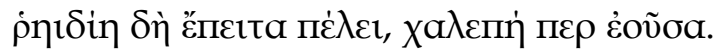

Heródoto, Unifesp, Guarulhos, v. 5, n. 2 - 2020.2, p. 31-47.

DOI: $10.34024 /$ herodoto.2020.v5.12832 
A ti, infantil Perses, te hablaré yo, conocedor de las cosas nobles.

Se puede, por cierto, alcanzar la maldad, incluso en abundancia,

fácilmente; llano es el camino, y muy cerca se encuentra;

pero delante de la virtud, sudores han puesto los dioses

inmortales; amplia y recta la senda hacia ésta,

escabrosa al principio; pero a medida que a la cima accedes,

fácil entonces se vuelve, por difícil que sea. (Trabajos y Días, 286-292)

$\mathrm{O}$ advérbio $\dot{\eta}\rceil \delta i \omega s$, facilmente, comodamente, afavelmente; e o adjetivo $\lambda \varepsilon i ̃ o s$, plano, natural, fácil figuram o acesso cômodo à maldade. Mas, diante

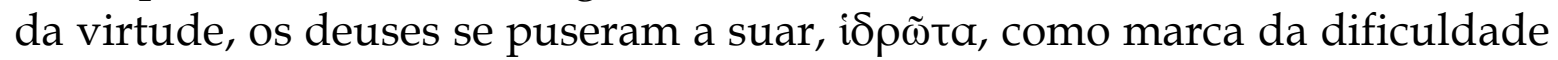
que implica alcançar a excelência. Há um termo chave que permite associar virtude e trabalho; io $\rho \omega$ s significa suor, mas seu plural alude precisamente a esforços, trabalhos.

A virtude é um trabalho e seu caminho é íngreme e difícil. Hesíodo parece ser o precursor de outras trajetórias filosóficas que descrevem o árduo caminho para a excelência. Este é um ensinamento capital. Este é o verdadeiro kairós para distinguir a maldade da virtude e seus respectivos caminhos. Hesíodo não opõe apenas a dois valores antagônicos, mas sua mensagem vai ao âmago da subjetividade. O desafio é persuadir Perses das vantagens de um caminho sobre o outro além de sua aparente facilidade.

É o fato pedagógico de inculcar um valor, que vai além de Perses e abraça toda a comunidade. Concordamos com A. Edwards quando ele diz "Althoug Hesiod's position may be dictated by his own self interest, he strives to formulate his appeal to Perses in the language of values that held the respect and guided the behavior of members of the community" (2004: 177).

Os versos que a seguir reafirmam o valor do ensino, ratificando os papéis daquele que aconselha e daquele que se deixa aconselhar. Há uma revalorização daquele que compreende o que foi ensinado e incorpora o valor depois de meditar sobre sua beleza e benefício. O campo lexical do verbo $\Phi \rho a ́ \zeta \omega$, pensar, refletir, meditar, se dar conta, faz com que o trabalho se origine da inteligência ou compreensão, vónors. É, de fato, a inteligência que reconhece o valor da virtude e torna o homem muito superior, navápıбos.

Heródoto, Unifesp, Guarulhos, v. 5, n. 2 - 2020.2, p. 31-47.

DOI: $10.34024 /$ herodoto.2020.v5.12832 
Tão superior e nobre quanto aquele que sabe receber conselhos de quem tem autoridade para oferecê-los.

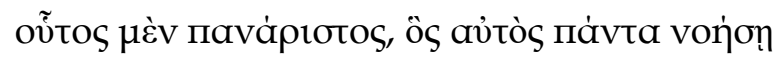

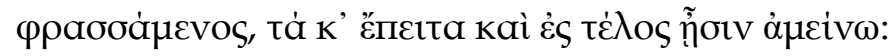

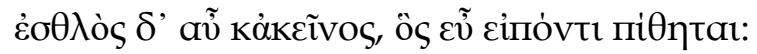

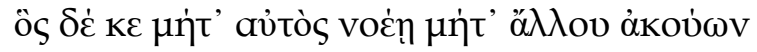

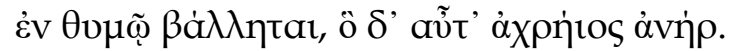

Así, muy superior es quien por sí mismo todo comprende

después de meditar lo que entonces y al fin es lo mejor,

y noble a su vez aquél que obedece a quien bien aconseja;

pero el que no comprende por sí mismo, ni escuchando de otro

en su ánimo lo guarda, ése, pues, es un hombre inútil. (Trabajos y Días, 293-297)

A presença do verbo пєiӨ $\omega$, persuadir, aconselhar, marca um ponto central na experiência educacional. De fato, na arte de transmitir uma verdade, há algo da ordem da persuasão, até mesmo da sedução. O professor se torna confiável, crível, e por isso o ensino é eficaz.

Hesíodo insiste em opor dois tipos de atitudes que determinam dois tipos de homens. O homem nobre que pode refletir por si mesmo e valorizar o que

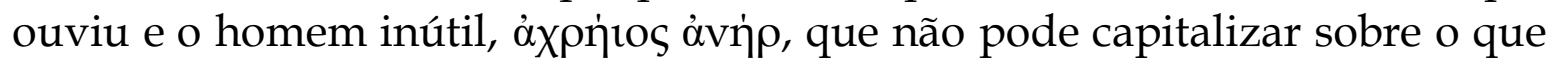
aprendeu. $\mathrm{O}$ adjetivo é eloquente a este respeito: inútil, inepto.

A chave da nobreza está, então, no desenvolvimento de duas atitudes que mostram em que sentido a educação se torna kairós: compreender e ouvir dois elementos que antropologicamente distinguem os homens mortais dos animais.

Cronos não só deu aos homens justiça, mas também a capacidade de refletir por si mesmos e de ouvir os conselhos daqueles que têm autoridade para aconselhar. São estas reflexões que nos colocam diante de um Hesíodo pensador, uma figura que se esforça por uma verdadeira sabedoria de vida.

Heródoto, Unifesp, Guarulhos, v. 5, n. 2 - 2020.2, p. 31-47.

DOI: $10.34024 /$ herodoto.2020.v5.12832 
Concordamos com H. Koning sobre a afirmação "When Hesiod is alone, things are very different. From its earliest reception onwards, the Greek regarded the Theogony as a textbook of great philosophical import (comparable to the Works and Days in the field of ethics" (2010: 189).

\section{O Trabalho}

Iniciamos nossa pesquisa com os documentos da mais antiga era pós-Homérica, nos quais, embora ainda não esteja estabelecida uma distinção entre trabalho manual e intelectual, o problema da valorização do trabalho já está colocado no conflito entre a dolorosa experiência e a consciência de que ela representa o caminho obrigatório para prover a própria existência e para estabelecer o próprio direito à vida. É precisamente Hesíodo, em Os Trabalhos e os Dias, que mostra tal duplicidade de tendências em contraste mútuo, característica da situação espiritual do trabalhador. (Mondolfo, 1969: 361).

Chegamos então ao terceiro baluarte em que a educação aparece como a oportunidade para uma possível transformação. O trabalho constitui a alma mater do poema.

É o núcleo problemático que desdobra o significado último do poema e da função didática de Hesíodo. É, ao mesmo tempo, o elemento que sintetiza os outros dois elementos trabalhados até se tornarem uma unidade indissolúvel, associada, por outro lado, ao poder. Referimo-nos ao poder de quem recebeu uma educação dura no que se refere aos valores da justiça, da virtude e do trabalho. Este é um homem nobre e eticamente poderoso.

Selecionamos apenas alguns versos emblemáticos para percorrer o tema porque, de fato, todo o poema é dedicado a ele. O calendário do lavrador é a prova mais irrefutável desta preocupação com a excelência do trabalho.

Há apenas uma noção registrada no proêmio do lavrador. Os trabalhos no campo são regulados pelos ciclos cósmicos. A ideia de tempo implica, por um lado, o reconhecimento do lapso de tempo que vai do começo ao fim; por outro, nesse segmento, dias e noites se sucedem, evidenciando a ordem que o universo conserva em sua regulação cósmica. "Esta é a lei dos campos" (Trabajos y días, 399), adverte o poeta antes de recomendar como semear. $\mathrm{O}$ campo e o trabalho que é feito nele obedecem a uma legalidade que submete tanto o espaço quanto a atividade a uma ordem que não pode ser alterada. Acreditamos que esta ordem pode ser inscrita no que Mario Vegetti entende Heródoto, Unifesp, Guarulhos, v. 5, n. 2 - 2020.2, p. 31-47.

DOI: $10.34024 /$ herodoto.2020.v5.12832 
por "sagrado" quando afirma: "Sagrado é também, portanto, a ordem da natureza, a sucessão das estações, das colheitas, do dia e da noite" (1993: 296). A ordem impõe a articulação entre as diferentes atividades. O projeto de sistematização que acreditamos descobrir em Hesíodo não deixa elementos entregues ao acaso. A vida do kósmos e a vida dos homens constituem um todo sujeito a regras específicas de funcionamento que nos faz pensar nas noções de sophrosyne e dike que sobrevoam as reflexões vertidas. Pensamos nisso a partir da ideia de limite presente na primeira noção e de justa medida delineada na segunda. O kósmos cobra legalidade e harmonia quando todos os seus elementos se ajustam e se encaixam em uma unidade cujos elementos inerentes respondem aos mesmos parâmetros organizacionais. Esta unidade é jogada na temporalidade, sendo esta ideia um dos eixos da própria cosmicidade.

É este esquema de organização e justiça que Hesíodo tenta incutir em Perses quando o adverte:

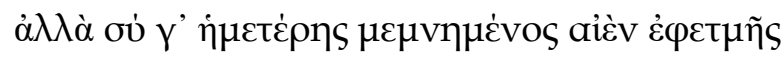

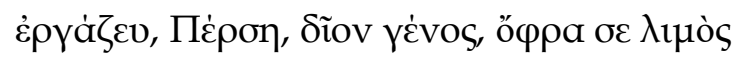

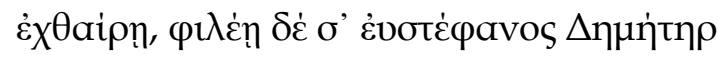

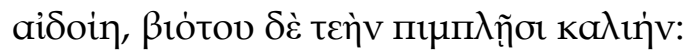

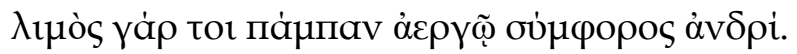

No obstante tú, recordando siempre nuestro mandato,

trabaja Peres, divino linaje, para que el hambre a ti

te aborrezca, y te ame la bien coronada Deméter

augusta y de sustento llene tu granero;

pues el hambre es sobre todo compañera del hombre ocioso. (Trabajos y Días, 298-302)

O campo lexical do verbo $\mu \iota \nu$ n் $\sigma \kappa \omega$, recordar, trazer à lembrança, trazer ao

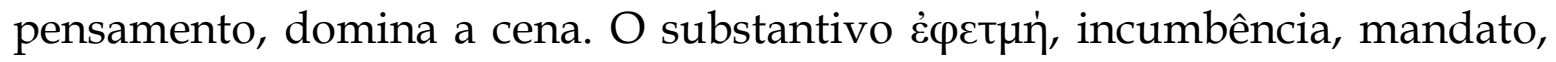
ordem, em consonância, completa a ação. A incumbência é abraçar o trabalho e compreender seu valor sagrado, como afirma Vegetti. Amostra dessa sacralidade é a menção da coroada Demeter, porque é ela quem finalmente se encarrega de encher o celeiro e garantir que a fome não transforme a vida de Perses em uma vida dolorosa.

Heródoto, Unifesp, Guarulhos, v. 5, n. 2 - 2020.2, p. 31-47.

DOI: $10.34024 /$ herodoto.2020.v5.12832 
O ensino do trabalho torna-se assim uma lição social e comunitária. Visa não apenas um valor individual, mas também a consolidação de uma comunidade mais justa e próspera. Concordamos com Koning quando ele afirma: "The Hesiodic idea of human interaction is also understood and explained in terms of balance and reciprocity" (2010: 177).

Há algo de reciprocidade e justiça no tema do trabalho, sobretudo porque o trabalho implica a responsabilidade de obter o próprio sustento sem depender do outro. Sabemos da rejeição tanto de mortais quanto de imortais daqueles que não fazem seu trabalho e vivem como um zangão. Desta forma, a educação no trabalho é ao mesmo tempo o kairós para definir um mapa social de maior reciprocidade, o que implica que ela constitui um verdadeiro articulador de elos.

A educação evidencia os alcances da preocupação ético-social do trabalho em Hesíodo, destacando seu protagonismo, o que sugere uma intensa preocupação com o vínculo trabalho-ethos-dike como um modo de vida ${ }^{4}$.

Ao mesmo tempo, a educação revela a importância do trabalho como fato cultural e como forma de estatuto antropológico, pois dá ao homem um domicílio existencial, ao mesmo tempo em que lhe mostra sua distância em relação aos imortais.

\section{Conclusões}

Nosso projeto de trabalho consistiu em analisar até que ponto a práxis educacional representa o kairós de uma possível transformação que atinge os diferentes níveis do pessoal e do comunitário. Desta forma, educação e kairós são noções conexas no cenário que se apresenta em Os Trabalhos e os Dias.

A atualidade do tema é inegável e faz de Hesíodo um clássico, como argumentamos na introdução. Tanto na antiguidade como hoje, a educação foi instituída como kairós de alguma transformação possível, tanto no indivíduo como na ordem social. É por isso que Hesíodo parece exercer um magistério particular, o que o coloca em um topos de autoridade.

\footnotetext{
${ }^{4}$ Concordamos com o posicionamento de Judet de La Combe e Lernould (1996: 302), quando afirmam que "l' travail apparaît comme l' activité qui définit l' homme essentiellment". Com efeito, a dissimetria ontológica entre os dois planos significa que o trabalho é definido a partir de um registro que vai além de sua dimensão funcional.
}

Heródoto, Unifesp, Guarulhos, v. 5, n. 2 - 2020.2, p. 31-47.

DOI: 10.34024/herodoto.2020.v5.12832 
Diante do cenário de degradação ética que permeia o poema, a educação se apresenta como o pilar da transformação, que nosso trabalho articulou em três eixos: justiça, virtude e trabalho. Unidade indissolúvel quando se trata de transmitir os valores que podem transformar a realidade como um todo.

As passagens escolhidas de Os Trabalhos e os Dias são aquelas em que Hesíodo, como professor, interpela seu irmão, dramatizando uma espécie de cena didática exemplar onde são instituídos papéis específicos, que dão ao poeta o lugar de um professor capaz de contar verdades que constituem, por sua densidade e profundidade, a oportunidade para a transformação que o autor espera, tanto no plano individual quanto no social.

Hesíodo aparece, sem dúvida, como um homem que responde a um tempo histórico. A conjuntura histórica é o meio de produção da inquietação que o separa de Homero e o lança em uma novidade que se situa nos limites do fazer filosófico.

Hesíodo descreve uma realidade que o aflige e, a partir desse pathos doloroso e desolador, ele responde de forma comprometida com o logos didático presente em Os trabalhos e os Dias.

Hesíodo mostra-se capaz de reconstruir a partir do logos poético a razão desta situação histórica em uma tentativa genealógica, sobretudo a partir do mito das idades como um logos exemplar e as consequências antropológicas de ter nascido no tempo que lhe coube viver.

Hesíodo pensa sobre seu tempo histórico e isto o coloca em uma posição privilegiada de testemunha de uma conjuntura histórico-antropológica que o impacta e o convoca a uma inquietação constante, como parece ser mostrado em Os Trabalhos e os Dias. Desta forma, Hesíodo torna-se uma testemunha lúcida e comprometida de seu tempo, assumindo, de certa forma, o comando de seu próprio presente e investigando suas possíveis condições. Esta é uma dimensão genealógica que abordaremos a partir de um fundo interpretativo diferente da configuração usual do termo genealogia, tão próximo da Teogonia, como uma obra emblemática do modelo teogônico. Embora tenhamos percorrido a genealogia presente no poema, optamos por uma virada interpretativa no termo tal como é utilizado por Nietzsche ou Michel Foucault.

Heródoto, Unifesp, Guarulhos, v. 5, n. 2 - 2020.2, p. 31-47.

DOI: $10.34024 /$ herodoto.2020.v5.12832 
Finalmente, queremos expressar que é esta consideração da presente questão e este contato com o problema como marca histórica-existencial que afasta Hesíodo de Homero. Não percebemos na épica homérica essa preocupação com a conjuntura histórica, o que não implica, é claro, uma avaliação negativa da obra homérica. Acreditamos ver em Hesíodo um atalho de novidade diante da problemática de Homero que passa por outros percursos, não menos ricos. Muito trabalho tem sido feito sobre as marcas de diferença entre um e outro, talvez com o propósito silencioso de engrandecer a figura de Hesíodo em oposição à soberania homérica. Nossa perspectiva, entre outras, visa pensar nesta questão de preocupação ou inquietação em relação ao tempo em que se vive, como um patrimônio hesiódico de forte impacto em sua obra, especialmente em Os Trabalhos e os Dias.

Hesíodo permite prever as possibilidades de um futuro melhor, a partir de certas bases de reconstrução do tempo presente, fundamentalmente codificadas em sua proposta didática.

\section{Fontes}

HESÍODO. Obras y fragmentos. Madrid: Gredos, 2000.

HESIOD. Theogony. Works and Days. Testimonia. Most, G. W. (editor y traductor). Loeb Classical Library. London: Harvard University Press, 2006.

LIDDEL, H. G., SCOTT, R. A Greek-English Lexicon. Oxford: Clarendon Press, 1996.

LIÑARES, Lucía. Hesíodo Teogonía, Trabajos y Días. Edición bilingüe. Buenos Aires: Losada, 2005.

VIANELLO DE CÓRDOVA, Paola. Hesíodo Teogonía. México: Universidad Nacional Autónoma de México, 1978.

\section{Bibliografia}

COLOMBANI, María Cecilia. Hesíodo. Discurso y Linaje. Una aproximación arqueológica. Mar del Plata: EUDEM, 2016.

DETIENNE, Marcel. Los maestros de verdad en la Grecia Arcaica. Madrid: Taurus, 1986.

EDWARDS, Anthony T. Hesiod's Ascra. London: University of California Press, 2004.

GERNET, Louis. Antropología de la Grecia Antigua. Madrid: Taurus, 1981.

GIGON, Olof. Los orígenes de la filosofía griega. Buenos Aires: Gredos, 1985.

Heródoto, Unifesp, Guarulhos, v. 5, n. 2 - 2020.2, p. 31-47.

DOI: $10.34024 /$ herodoto.2020.v5.12832 
HUNTER, Richard. Hesiodic Voices. Studies in the Ancient Reception of Hesiod's Works and Days. Cambridge Classical Studies Cambridge University Press, 2014.

JUDET DE LA COMBE, Pierre y LERNOULD, Alain. Sur le Pandore des Travaux. Esquisses en BLAISE, Fabienne, JUDET DE LA COMBE, Pierre et Rousseau, Philippe (eds.) Le métier du mythe. Lectures d' Hésiode, Paris: Presse Universitaires du Septentrion, 1996.

KONING, Hugo. Hesiod. The other poet. Ancient Reception of a Cultural Icon. Boston- Leiden: Brill, 2010.

MONDOLFO, Rodolfo. La comprensión del sujeto humano en la cultura antiguaBuenos Aires: EUDEBA, 1969.

NESCHKE, A. Dikè. La philosophie poétique du droit dans le "mythe des races" d' Hésiode en BLAISE, Fabienne, JUDET DE LA COMBE, Pierre et Rousseau, Philippe (eds.) Le métier du mythe. Lectures d' Hésiode, Paris: Presse Universitaires du Septentrion, 1996.

VEGETTI, Mario. El hombre y los dioses en VERNANT Jean-Pierre (ed.) El hombre griego. Madrid: Alianza, 1993.

Heródoto, Unifesp, Guarulhos, v. 5, n. 2 - 2020.2, p. 31-47.

DOI: $10.34024 /$ herodoto.2020.v5.12832 